\title{
Stroke in patients with diabetes mellitus: a study from North Western Nigeria.
}

\author{
Lukman Owolabi ${ }^{1}$, Mansur Nagode ${ }^{2}$, Aliyu Ibrahim ${ }^{1}$, Andrew Uloko ${ }^{1}$, \\ Ibrahim Gezawa ${ }^{1}$, Mohammad Datti ${ }^{1}$
}

1. Aminu Kano Teaching Hospital, Bayero University.
2. Murtala Muhammad Specialist Hospital, Department of Medicine.

\begin{abstract}
Background: Stroke is one of the major causes of morbidity and mortality worldwide and apart from being exceedingly harmful in diabetics, stroke is a disabling disorder. The study was undertaken to describe the clinical characteristics, outcome pattern and predictors of mortality in a cohort of diabetic patients presenting with stroke in two tertiary health facilities in North Western Nigeria.

Method: Out of all stroke patients seen from June 2007 to February 2011, persons with diabetes mellitus presenting with stroke in the emergency unit of the two tertiary hospitals in Kano were consecutively recruited for the study. Classification of stroke into hemorrhagic and infarctive subtypes was based on brain computerized tomography (CT), brain magnetic resonance imaging (MRI) and World Health Organization (WHO) criteria. Follow-up period was for thirty days.

Result: Out of the five hundred and thirty six stroke patients seen during the study period, 85 (15.9\%) patients, comprising 48 $(56.5 \%)$ males, had diabetes. Thirty eight $(44.7 \%)$ of the identified diabetics were previously undiagnosed. Sixty four $(75.3 \%)$ had infarctive stroke. One-month case fatality rate was 30.6\%. Factors associated with death included male sex, past history of TIA, abnormal respiratory pattern, hemorrhagic stroke, aspiration pneumonitis, and worsening GCS. Aspiration pneumonitis and worsening GCS were independent predictors of one month mortality of stroke in the patients.
\end{abstract}

Conclusion: In DM patients studied, infarctive stroke was more common, case fatality was $30.6 \%$. Male gender, past history of TIA, abnormal respiratory pattern, hemorrhagic stroke, aspiration pneumonitis, and worsening Glasgow Coma Score (GCS) were associated with mortality. Aspiration pneumonitis and worsening GCS were independent predictors of one month mortality of stroke in diabetic patients.

Keywords: Stroke, diabetes, stroke, Nigeria.

DOI: http://dx.doi.org/10.4314/ahs.v16i3.19

Cite as: Owolabi L, Nagode M, Ibrabim A, Uloko A, Gezawa I, Datti M. Stroke in patients with diabetes mellitus: a study from Northwestern Nigeria. Afri Health Sci 2016;16(3): 781-789. DOI: bttp://dx.doi.org/10.4314/abs.v16i3.19

\section{Introduction}

Patients with diabetes mellitus (DM) are more susceptible to develop vascular diseases, including stroke. Stroke is one of the leading causes of morbidity and mortality worldwide $^{1,2}$ and apart from being exceedingly harmful in diabetics, stroke is a disabling disorder. ${ }^{3}$

Like in many other African countries, there is a paucity of data on the prevalence of diabetes in Nigeria. However, available data suggests that the prevalence varies
Corresponding author:
Lukman Owolabi,
Aminu Kano Teaching Hospital,
Bayero University, Neurology unit,
Department of Medicine
Email: drlukmanowolabi@yahoo.com

from $0.65-11 \%{ }^{4}$ and that diabetes is increasingly emerging as a major health problem in Africa, including Nigeria. ${ }^{5}$ It is predicted that the prevalence of DM in adults will increase in the next two decades and that much of the increase will occur in developing countries where the majority of patients are aged between 45 and 64.5. ${ }^{6,7}$

Diabetes mellitus (DM) is one of the established risk factors for stroke. ${ }^{8}$ Several studies have reported increased risk of stroke in patients with diabetes. ${ }^{9-11}$ In Nigeria, a multicenter study showed that $4.7 \%$ of diabetic patients had stroke. ${ }^{12}$ In Kano, North Western Nigeria, DM was one of the leading risk factors of stroke both in the young and adults. ${ }^{13-15}$

Several studies have reported increased mortality from stroke in the diabetic patients. ${ }^{16,17}$ Furthermore, various studies have also shown that stroke patients with DM have higher in-hospital mortality rates and poorer outcome than those without diabetes. ${ }^{18,19}$

African Health Sciences Vol 16 Issue 3, September 2016 
Thus, exploration of the clinical pattern, the outcome as well as factors associated with mortality and independent predictors of mortality of stroke in patients with diabetes is necessary for optimal prevention and management of stroke in this group of patients.

The objective of the study was to describe the clinical characteristics, outcome pattern and factors that predict mortality in a cohort of diabetic patients in two tertiary health facilities in Kano, North Western Nigeria.

\section{Materials and method}

In this prospective study, patients with diabetes mellitus (DM), including those that were previously and newly diagnosed, presenting with stroke from stroke from various etiologies were recruited in the emergency unit, medical wards and neurology clinics of the two tertiary hospitals (Aminu Kano Teaching Hospital (AKTH), Kano and Murtala Muhammad Specialist Hospital, (MMSH) Kano) from June 2007 to February 2011. Eligibility for the study was in accordance with the World Health Organization (WHO) definition of stroke as clinical signs of focal (or global) disturbance of cerebral function, with symptoms lasting 24 hours or longer or leading to death, with no apparent cause other than vascular origin. ${ }^{20}$ Diabetes mellitus was defined and diagnosed in accordance to WHO criteria of $1999 .{ }^{21}$ All the patients enrolled were assessed by neurologists experienced in the subtlety of stroke diagnosis, typing and management. Classification of stroke into hemorrhagic and infarctive stroke subtypes was based on Brain CT or MRI. The WHO stroke scale was also used in some patients who by reason of cost or otherwise could not do the test. The WHO criterion has a sensitivity of $73 \%$ for hemorrhage and $69 \%$ for infarction and an overall accuracy of $71 \%$ in Nigeria. ${ }^{20}$

Patients with ambiguous clinical and/or radiological diagnosis of stroke were excluded from the study. Each diagnosed patient was followed up for thirty days until either death at the hospitals or discharge.

At presentation, patients and/or relatives were interviewed to obtain information pertaining to the onset of stroke and pre-existing risk factors, including hypertension, DM, hyperlipidaemia, smoking, ischemic heart disease, atrial fibrillation and previous transient ischemic attacks.

A standardized data sheet was used to record the demographic variables including sex, age (If the exact age of the patient was not known, it was calculated by estimating their age at the time of significant events in Nigeria, previous stroke, seizure, blood pressure in recumbent position, pulse, axillary temperature, respiratory rate and pattern, GCS, pupillary size, pupillary reaction, presence of aspiration pneumonitis, co-morbidities, length of stay, outcome (dead or alive all through 30 days), time of death, random blood sugar at presentation and lipid profile at presentation were recorded. Variation of certain parameters such as pupillary size and B.P was minimized by recording only average findings of at least two examiners.

During their hospital stay, patients received standard care, however, they were managed in the general medical wards due to lack of stroke units in the facilities. The patients were treated in accordance with Aminu Kano Teaching Hospital guideline on stroke management, which is a modification of the American Heart Association / American stroke association (AHA/ASA) guidelines. ${ }^{23}$

Analysis of data was carried out using the STATA version 11( Statacorp LP, College station, Texas, USA). Bivariate analysis was carried out using Chi-square or Fisher exact test for categorical variables and student's t test was used to compare the means of continuous variables. A $\mathrm{P}<0.05$ was used as a significant level. Multiple logistic regression model was used and the covariates were adjusted for each independent (regression) variable to find independent predictors of in-hospital mortality. Variables included in the regression model were those that had a significant $\mathrm{P}$ value $(\mathrm{P}<0.05)$ in the bivariate analysis. Survival rate was calculated using the Kaplan-Meier method. Ethical approval was obtained from the AKTH and MMSH institutional review board for the study.

\section{Result}

Out of the five hundred and thirty six stroke patients seen during the study period eighty five $(15.9 \%)$ had diabetes. Their age ranged between 38 and 80 years (Figure 1) with a mean age of $56.1 \pm 10.1$. 


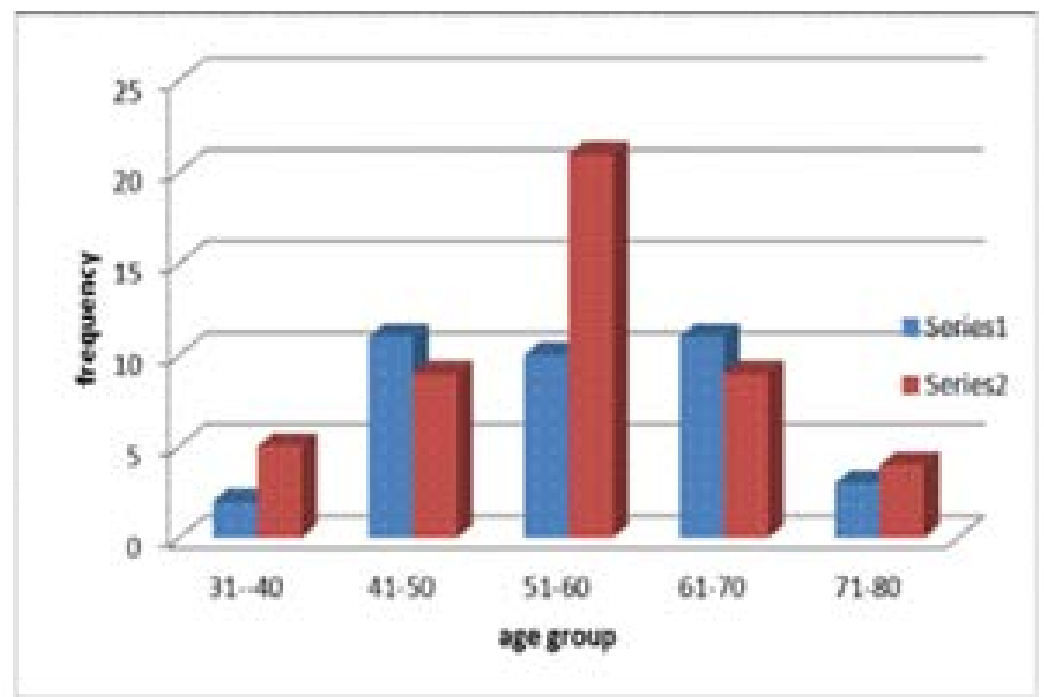

Figure 1. Distribution of age of the patients by their gender (scries $1=$ male, series $2=$ female).

There were forty eight $(56.5 \%)$ males in the study. The mean age of the males and female patients were 56.0 \pm 1.5 and $56.2 \pm 1.6$ respectively, however, the difference was not statistically significant $(p=0.5517)$. Twenty two $(25.9 \%)$ patients had diabetes only while sixty three $(74.1 \%)$ had other cardiovascular risk factors including hypertension, hypercholesterolemia and smoking. Thirty eight $(44.7 \%)$ patients were unaware of their diabetic status before hospitalization. Seventy five (88.2\%) had neuroimaging. Sixty four $(75.3 \%)$ had an infarctive stroke while hemorrhagic stroke was present in twenty one $(24.7 \%)$ all of which were intracerebral hemorrhages. Diabetes coexisting with hypertension $(57.1 \%)$ was more associated with hemorrhagic stroke when compared with those $(42.1 \%)$ with diabetes only and the relationship was statistically significant $(p=0.041)$. Twenty one $(24.4 \%)$ of the patients had a history of transient ischemic attack. Result of serum cholesterol was available in seventy three $(85.9 \%)$ patients. Twenty seven had elevated LDL; twenty two had low HDL while thirty four had elevated triglycerides. Fifty one $(69.9 \%)$ had one form of serum cholesterol or another elevated.

One-month case fatality rate in the study patients was $30.6 \%$. Out of the twenty six deaths recorded during the study period, eighteen $(69.2 \%)$ occurred in the first 72 hours (Figure 2). 


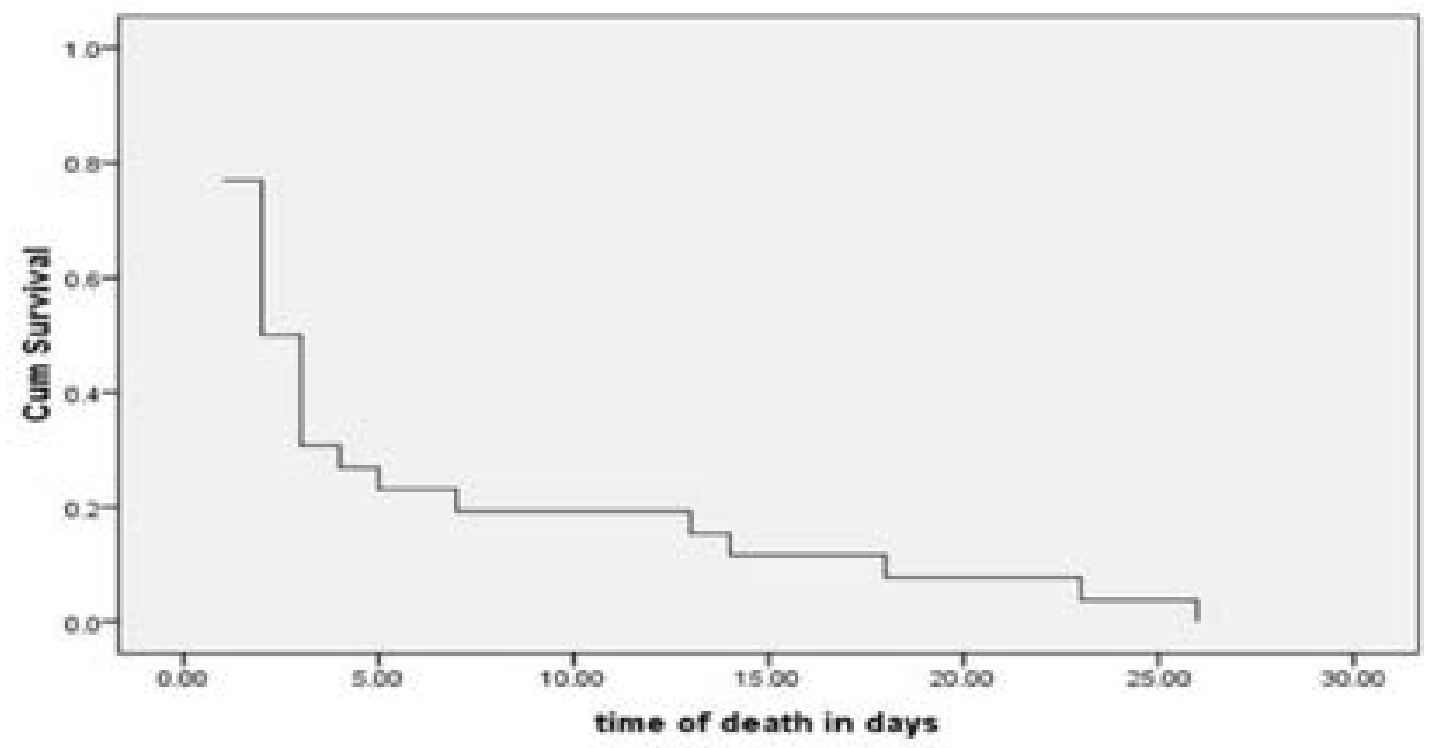

Nigure 2. Kaplan Meicr survival curve showing result of survival data of the paticnts

Two $(2.4 \%)$ patients were lost to follow up after discharge from the hospital. At bivariate analysis, the factors that were found to be significantly related with mortality were male sex, past history of TIA, abnormal respiratory pattern, abnormal pupillary size and reaction, abnormal serum urea level, hemorrhagic stroke, aspiration pneumonitis, and worsening GCS (table 1). 
Table 1. Factors associated with 1-month mortality

\begin{tabular}{|c|c|c|c|}
\hline \multirow[t]{2}{*}{ Factors } & \multicolumn{2}{|c|}{ Proportion of patients who died } & \multirow[t]{2}{*}{$\mathrm{P}$ value } \\
\hline & $\begin{array}{l}\text { Proportion } \\
\text { (N/Total) }\end{array}$ & $\%$ & \\
\hline \multicolumn{4}{|l|}{ Sex } \\
\hline Male & $10 / 48$ & 20.8 & \multirow[t]{2}{*}{$0.026 *$} \\
\hline Female & $16 / 37$ & 43.2 & \\
\hline \multicolumn{4}{|l|}{ Education } \\
\hline Not educated & $20 / 67$ & 29.9 & \multirow[t]{2}{*}{0.776} \\
\hline Educated & $6 / 18$ & 33.3 & \\
\hline \multicolumn{4}{|l|}{ History of TIA } \\
\hline Present & $13 / 21$ & 61.9 & \multirow[t]{2}{*}{$0.001 *$} \\
\hline Absent & $13 / 64$ & 20.3 & \\
\hline \multicolumn{4}{|c|}{ Abnormal respiratory pattern } \\
\hline Present & $12 / 56$ & 21.4 & \multirow[t]{2}{*}{$0.011 *$} \\
\hline Absent & $14 / 29$ & 48.3 & \\
\hline \multicolumn{4}{|l|}{ Papillary size } \\
\hline Abnormal & $22 / 39$ & 56.4 & \multirow[t]{2}{*}{$0.004 *$} \\
\hline Normal & $4 / 46$ & 8.7 & \\
\hline \multicolumn{4}{|l|}{ Papillary reaction } \\
\hline Abnormal & $21 / 39$ & 53.9 & \multirow[t]{2}{*}{$0.000 *$} \\
\hline Normal & $5 / 46$ & 10.9 & \\
\hline \multicolumn{4}{|c|}{ Presence of comorbidity } \\
\hline Present & $12 / 22$ & 54.6 & \multirow[t]{2}{*}{$0.005^{*}$} \\
\hline Absent & $14 / 63$ & 22.2 & \\
\hline \multicolumn{4}{|l|}{ Serum urea level } \\
\hline Abnormal & $4 / 54$ & 7.4 & \multirow[t]{2}{*}{$0.000 *$} \\
\hline Normal & $30 / 34$ & 88.2 & \\
\hline \multicolumn{4}{|c|}{ Serum cholesterol level } \\
\hline Abnormal & $15 / 51$ & 29.4 & \multirow[t]{2}{*}{0.556} \\
\hline Normal & $5 / 22$ & 22.7 & \\
\hline \multicolumn{4}{|l|}{ Stroke type } \\
\hline Ischemic & $9 / 64$ & 14.1 & \multirow[t]{2}{*}{$0.000 *$} \\
\hline Hemorrhagic & $17 / 21$ & 81.0 & \\
\hline \multicolumn{4}{|c|}{ Aspiration pneumonitis } \\
\hline Present & $16 / 33$ & 48.5 & \multirow[t]{2}{*}{$0.004 *$} \\
\hline Absent & $10 / 52$ & 19.2 & \\
\hline \multicolumn{4}{|l|}{ RBS } \\
\hline$>200 \mathrm{mg}$ & $13 / 32$ & 40.6 & \multirow[t]{2}{*}{0.119} \\
\hline$<200 \mathrm{mg}$ & $13 / 53$ & 24.5 & \\
\hline $\mathrm{GCS} * *$ & & & $0.000 *$ \\
\hline Age*** & & & 0.258 \\
\hline
\end{tabular}

$* \mathrm{P}=$ statistically significant

However, after adjusting for confounding variables aspiration pneumonitis and worsening GCS were found to be the only independent predictors of one month mortality of stroke in patients with DM (Table 2 \& Figure 3). 
Table 2. Multivariate analysis to determine independent predictors of mortality.

\begin{tabular}{|l|l|l|l|l|}
\hline Factors & \multirow{2}{*}{ Odds ratio } & \multicolumn{2}{|l|}{$95 \%$ Confidence interval } & \multirow{2}{*}{ P value } \\
\cline { 3 - 4 } & & Lower & Upper & \\
\hline Sex(male) & 0.621 & 0.095 & 4.042 & 0.618 \\
History of TIA & 0.466 & 0.077 & 2.825 & 0.407 \\
Abnormal respiratory pattern & 0.457 & 0.137 & 1.522 & 0.202 \\
Aspiration pneumonitis & 0.040 & 0.002 & 0.811 & $0.036^{*}$ \\
Worsening GCS & 2.107 & 1.063 & 4.177 & $0.033^{*}$ \\
Presence of comorbidity & 1.343 & 0.090 & 20.096 & 0.831 \\
Abnormal pupillary size & 0.122 & 0.011 & 1.398 & 0.091 \\
Abnormal pupillary reaction & 0.189 & 0.016 & 2.235 & 0.186 \\
\hline
\end{tabular}

$* \mathrm{P}=$ statistically significant

\section{Multivariate analysis for predictors of one-month mortality}

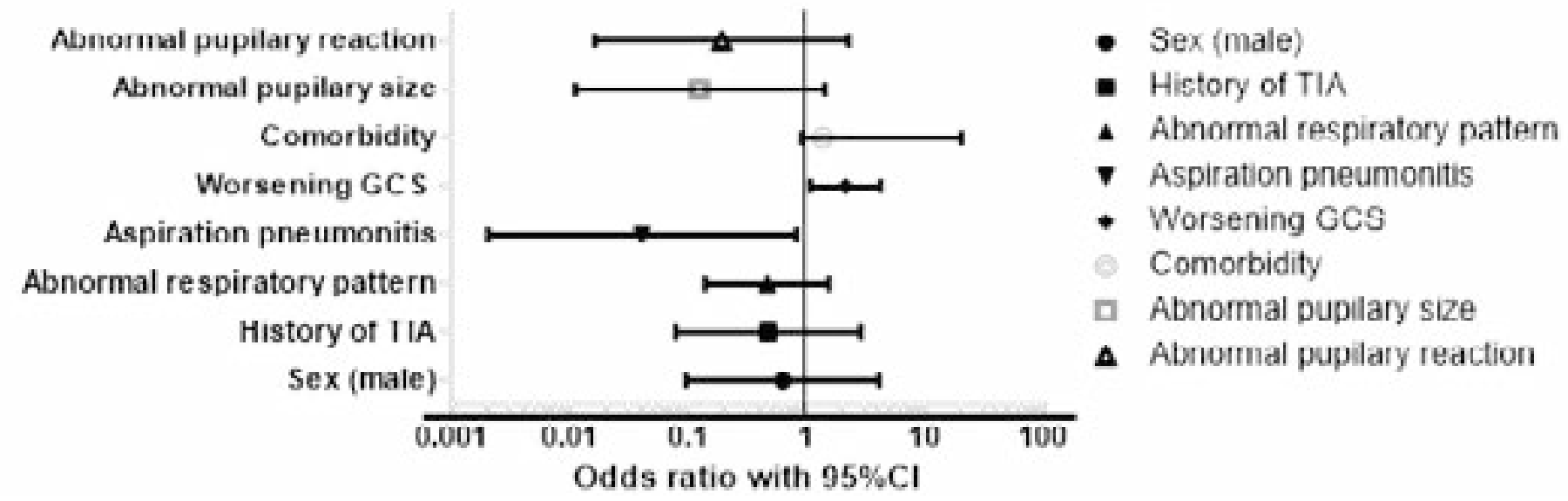

Figure 3: Odds ratio plot showing independent predictors of death

\section{Discussion}

In this hospital based study, diabetes mellitus, singly or in combination with other stroke risk factor was frequently seen in patients with stroke in the two tertiary health facilities that were studied. This finding is comparable with reports from developed and developing countries. ${ }^{24,25}$ Several large population studies have shown an increase in the prevalence of stroke in the known diabetic population, the undiagnosed diabetic population, and those with glucose intolerance. ${ }^{26}$ In reports from case control studies and prospective epidemiologic studies, DM has been shown to have an independent effect on ischemic stroke in both men and women, with an increased relative risk in diabetics ranging from 1.8 to nearly 6 -fold. ${ }^{27}$ Given that DM portends an increased susceptibility to developing atherosclerosis, it is very likely that it is a risk factor that plays a pivotal role in the vascular pathology that underlies stroke.

About $45 \%$ of the patients in the current study had no prior knowledge of their diabetic status before developing stroke. This observation was possibly a reflection of low level of education about diabetes in the general population in Nigeria. In a survey in Port Harcourt, South Nigeria only $58.8 \%$ of the diabetic population in the study were previously known to have diabetes. ${ }^{28}$ In a similar survey in Tanzania only $13.5 \%$ of the 53 diabetic subjects were previously known to have diabetes. ${ }^{29}$ However, the figure in this study is significantly less than that reported in the Copenhagen stroke study in which $75 \%$ of the dia- 
betics had known DM prior to their stroke, whereas DM was diagnosed in the remaining $25 \%$ of patients during hospitalization for their stroke. ${ }^{19}$ Our finding further underscores the need to intensify efforts on public awareness in respect of DM as stroke is largely preventable.

Three out of every four patients in this study, diabetes coexisted with hypertension.

This finding, which agreed with previous reports ${ }^{10}$, strengthens the fact that diabetes and hypertension often occur as co-morbidities. ${ }^{30,31}$

The majority $(75 \%)$ of the patients in the study had infarctive stroke. This figure is much higher than that previously reported $(63.7 \%)$ on stroke from all causes in the same population. ${ }^{14}$ Preponderance of infarctive stroke among diabetic patients with stroke in this study could be ascribed to the increased susceptibility of DM patients to vasculopathy, involving both small and large arteries, from atherosclerosis. Infarction occurring in the distribution of these arteries is usually of thrombo-embolic origin. $^{3}$ A population-based cohort study of 1192 patients that examined at a 5 year interval the progression of intima-media thickness on ultrasound studies of the common carotid artery, revealed that internal carotid artery intima-media thickening was approximately twice the rate in diabetics compared with non-diabetics. ${ }^{3,32}$

A lower frequency of hemorrhagic stroke recorded in this study was in agreement with a lower frequency of intracerebral hemorrhages in diabetic patients observed by Lithner et $\mathrm{al}^{33}$ and by Kiers et al. ${ }^{34}$ Unlike for chronic hypertension and hemorrhagic stroke, most case control studies examining the relationship between DM and hemorrhagic stroke have not concluded that DM is an independent risk factor for both intracerebral and subarachnoid hemorrhagic stroke. ${ }^{3}$ This probably explains why most of the diabetic patients with hemorrhagic stroke in our study also had hypertension.

Overall, one-month case fatality in this study was about $30 \%$ with a higher number of death recorded in patients with hemorrhagic than among those with ischemic stroke subtypes. This figure was comparable to what was reported from studies on stroke from all causes in Nigeria. ${ }^{14,35,36}$ Most of the deaths recorded in the study occurred within the first 72 hours. This finding is in agreement with a study conducted elsewhere. ${ }^{37}$
A prospective design of this study added strength to the study. However, some of the patients discharged within thirty days of follow-up were lost to follow-up, hence; deaths within a few days of discharge might have been missed constituting a limitation of the study.

Most of the deaths recorded in this study occurred in the first week of the stroke. This finding is in agreement with studies conducted elsewhere. ${ }^{37,38}$ Bamford et al attributed early death within the first 7 days to direct effects of neurological damage, whereas deaths during 7-30 days were mainly from immobility. ${ }^{39}$

Of note in the current study was the finding that there was no relationship between random blood sugar at presentation and 1-month in- hospital mortality. This finding is consistent with Copenhagen stroke studies which showed that there was no relation between admission blood glucose levels and mortality. ${ }^{19}$ A similar finding has also been reported from studies conducted elsewhere, ${ }^{34,}$ ${ }^{40}$ however, very few studies demonstrated an increased mean glucose level and mortality in diabetic patients. ${ }^{33}$ Nonetheless, in non-diabetic patients with stroke, several ${ }^{41-42}$ but few have found an increased mortality in hyperglycemic non-diabetic patients compared with euglycemic non-diabetic patients. ${ }^{40,43}$

One of the key findings of our study was that, out of the factors such as male sex, past history of TIA, abnormal respiratory pattern, abnormal pupillary size and reaction, abnormal serum urea level, hemorrhagic stroke, aspiration pneumonitis, and worsening GCS that were found to be significantly related to mortality only aspiration pneumonitis and worsening GCS independently predicted stroke mortality for diabetic patients with stroke. This finding, which was consistent with reports from studies conducted on stroke from all causes, ${ }^{42,45}$ has significant implication for treatment as, in resource poor setting, identification of predictors of death is of paramount importance for clinicians, so that specific therapies and management strategies can be applied to patients at high risk of dying.

Nonetheless, apart from the earlier mentioned limitation encountered in the course of this study, the fact that not all the patients had neuroimaging, which could cause an error of misclassification, is also worthy of mention. ${ }^{46,47}$ 


\section{Conclusion}

Diabetes mellitus was a major risk factor for stroke, male gender, past history of TIA, abnormal respiratory pattern, abnormal pupillary size and reaction, abnormal serum urea level, hemorrhagic stroke, aspiration pneumonitis, and worsening GCS were significantly related to mortality. Aspiration pneumonitis and worsening GCS were independent predictors of one month mortality of stroke in diabetic patients. Thus, identification of these predictors of death to determine those at high risk of dying and administration of management strategies will reduce mortality in the patients.

\section{Conflict of interest}

The authors declare no conflict of interest.

\section{References}

1. Strong K, Mathers C, Bonita R. Preventing stroke: saving lives around the world. Lancet Neurol 2007;6:182-187 PubMed .

2. Sweileh WM, Sawalha AF, Al-Aqad SM, Zyoud SH, Al-Jabi SW. The epidemiology of stroke in northern Palestine: a 1-year, hospital-based study. J Stroke Cerebrovasc Dis 2008;17:406-411.

3. Nader A, Scott S. Diabetes Mellitus and Stroke. Diabetes and stroke 2005;17: 17-22.

4. Nathan DM, Cleary PA, Backlund JY,Genuth SM, Lachim JM, Orchard TJ, et al. Diabetes Control and Complications Trial/Epidemiology of Diabetes Interventions and Complications (DCCT/EDIC) Study Research group: Intensive Diabetes treatment and Cardiovascular Disease in patients with Type 1 diabetes. $N$ Engl J Med. 2005;353:2643-53

5. Murray CJL, Lopez AD. Alternative projections of mortality and disability by cause. 1992020 . Global burden of disease study. Lancet 1997; 349:1498-1504 PubMed

6. Yach D, Hawkes C, Hoffman KJ. The global burden of chronic disease: overcoming impediments to prevention and control. JAMA 2004; 291: 2616-2622 PubMed

7. Mbanya JC, Bonicci F, Nagan K, Guidelines for the Management of NIDDM in Africa. A consensus document, Greece, Novo Nordisk A/s, 1996, pp. 1 -/35.

8. Kissela BM, Khoury J, Kleindorfer D, et al. Epidemiology of ischemic stroke in patients with diabetes: the greater Cincinnati/Northern Kentucky StrokeStudy. Diabetes Care. 2005;28(2):355-9.

9. Abbott RD, Donahue RP, MacMahon SW, Reed DM,
Yano K. Diabetes and the risk of stroke: the Honolulu Heart Program. JAMA. 1987;257:949-952.

10. Davis PH, Dambrosia JM, Schoenberg BS, Shoenberg DG, Pritchard DA, Lilienfeld AM, Whisnant JP. Risk factors for ischemic stroke: a prospective study in Rochester, Minnesota. Ann Neurol. 1987;22:319-327.

11. Barrett-Connor E, Khaw KT. Diabetes mellitus: an independent risk factor for stroke? Am J Epidemiol. 1988;128:116-123.

12. Uloko AE, Ofoegbu EN, Chinenye S,et al, Profile of Nigerians with diabetes mellitus - Diabcare Nigeria study group (2008): Results of a multicenter study. Indian J Endocrinol Metab. 2012; 16(4):558-64.

13. Owolabi LF. Shehu MN, Shehu MY, Fadare J, Pattern of Neurological admissions in the tropics: Experience at Kano, Northwestern Nigeria. Annals of Indian Academy of Neurology 2010; 13 (3): 167-170.

14. Owolabi LF, Nagoda M, Stroke in developing countries: Experience at Kano, Northwestern Nigeria. Sudan J Med Sci 2012; 7: 9-14 PubMed .

15. Owolabi LF, Ibrahim A, Stroke in Young Adults: A prospective study from Northwestern Nigeria. ISRN Neurology 2012; 10: 1-5 PubMed .

16. Asplund K, Hagg E, Helmers C, Lithner F, Strand T, Wester P-O. The natural history of stroke in diabetic patients. Ada Med Scand. 1980;207:417-424.

17. Pulsinelli WA, Levy DE, Sigsbee B,Scherer P, Plum F. Increased damage after ischemic stroke in patients with hyperglycemia with or without established diabetes mellitus. JAMA. 1983;74:540-544.

18. Olsson T, Viitanen M, Asplund K, Eriksson S,Hagg E. The prognosis after stroke in diabetic patients. A controlled prospective study. Diabetologia 1990;33:244-249 PubMed .

19. Jřrgensen H, Nakayama H, Raaschou HO, Olsen TS. Stroke in patients with diabetes. The Copenhagen Stroke Study. Stroke 1994;25:1977-1984 PubMed

20. World Health Organization. Recommendations on stroke prevention, diagnosis, and therapy. Report of the WHO Task Force on Stroke and other Cerebrovascular Disorders. Stroke 1989; 20: 1407-1431 PubMed .

21. WHO: Definition, Diagnosis and Classification of Diabetes Mellitus and its Complications. Part 1, WHO, Geneva, 1999

22. OgunSA, Odusote KA. Effectiveness of high dose dexamethasone in the treatment in the treatment of acute stroke. West Afr. J. Med 2001;9: 1-6 PubMed . 
23. Harold P. et al Guidelines for the early management of adults with ischemic stroke. Stroke 2007; 38:1655-1711 24. Sweileh WS, Zyoud2 SH, Sawalha AF, Al-Jabi2 SW, Abu-Taha AS. Clinical characteristics, sex differences and inhospital mortality among stroke patients with and without diabetes mellitus Diabetologia Croatica 2011; 40 (2): 41-47.

25. Ugoya OS, Ugoya AT, Agaba IE, Puepet HF. Stroke in persons with diabetes mellitus in Jos, Nigeria. Nigerian Journal of Medicine. 2005; 15 (3): 215-8.

26. David SH, Bell MB Stroke in the Diabetic Patient. Diabetes Care 1994; 17 (3) :213 PubMed -219

27. Goldstein LB, Adams R, Becker K, et al., for the Members. AHA Stroke Council. Primary Prevention of Ischemic Stroke. A Statement for Healthcare Professionals from the Stroke Council of the American Heart Association. Circulation 2001; 103:163.

28. Nyenwe EA, Odia OJ, Ihekwaba AE, Ojule A, Babatunde S. Type 2 diabetes in adult Nigerians: a study of its prevalence and risk factors in Port Harcourt, Nigeria. Diabetes Research and Clinical Practice 2003; 62 : 177-/185.

29. McLarty DG, Swai AB, Kitange HM, et al. Prevalence of diabetes and impaired glucose tolerance in rural Tanzania, The Lancet 1989;1: 871-/875

30. Hamidon BB, Raymond AA. The Impact of Diabetes Mellitus on In-hospital Stroke Mortality. J Postgrad Med 2003;49:307-10 PubMed

31. Stearne MR, Palmer SL, Hammersley S, Franklin SL, Spivey RS, Levy JC, et.al. Tight blood pressure control and risk of macrovascular and microvascular complications in type 2 diabetes: UKPDS 38. Br Med J 1998;317:703-13 PubMed

32. Wagenknecht LE, Zaccaro D, Espeland MA, et al. Diabetes and progression of carotid atherosclerosis: the insulin resistance atherosclerosis study. Arterioscler Thromb Vasc Biol. 2003; 23(6):917-918.

33. Lithner F, Asplund K, Eriksson S, Hagg E, Strand T, Wester P-O. Clinical characteristics in diabetic stroke patients. Diabetes Metab 1988;14:15-19.

34. Kiers L, Davis SM, Larkins R, Hopper J, Tress B, Rossiter SC,Carlin J, Ratnaike S. Stroke topography and outcome in relation to hyperglycemia and diabetes. $J \mathrm{Neu}$ rol Neurosurg Psych. 1992;55: 263-270.
35. Ogun SA, Ojini FI, Ogungbo B, Kolapo KO, Danesi MA. Stroke in southwest Nigeria: a 10 -year review. Stroke 2005; 36:1120-2 PubMed .

36. Ghandehari K, Pourzahed A, Taheri M et al., "Estimation of Iranian stroke patients eligible for intravenous thrombolysis with tPA," International Journal of Stroke 2009; 4(4): 236.

37. Stegmayr B, Vinogradova T, Malyutina S, Peltonen M, Nikitin Y, Asplund K. Widening Gap of Stroke Between East and West. Eight- Year Trends in Occurrence and Risk Factors in Russia and Sweden. Stroke 2000; 31:2-8 PubMed .

38. Ong TZ, RaymondAA. Risk Factors for Stroke and Predictors of One-Month Mortality. Singapore Med J 2002 Vol 43(10):517-521.

39. Bamford J, Dennis MS, Sandercock P, Burn J, Warlow C. The frequency, cause and timing of death within 30 days of a first ever stroke: The Oxfordshire Community Stroke Project. J NeuroINeurosurg Psychiatr. 1990;53: 824-9 40. Toni D, Sacchetti ML, Argentino C, et al. Does hyperglycemia play a role on the outcome of acute ischaemic stroke patients? J Neurol. 1992;239: 382-386.

41. Pulsinelli WA, Levy DE, Sigsbee B, Scherer P, Plum F. Increased damage after ischemic stroke in patients with hyperglycemia with or without established diabetes mellitus. JAMA. 1983;74:540-544.

42. Oppenheimer SM, Hoffbrand BI, Oswald GA, Yudkin JS. Diabetes mellitus and early mortality after stroke. BMJ. 1985;291:1014-1015.

43. Olsson T, Viitanen M, Asplund K, Eriksson S, Hagg E. Prognosis after stroke in diabetic patients: a controlled prospective study. Diabetologia. 1990;33:244-249

44. Chambers BR, Norris JW, Shurvell BL, Hachinski VC. Prognosis of acute stroke. Neurology. 1987; 37: 221 225.

45. Bonita R, Ford MA, Stewart AW. Predicting survival after stroke: a three-year follow-up. Stroke. 1988;19: 669673

46. Ogun SA, Oluwole O et al. Misdiagnosis of stroke- a computerized tomography scans study. West Afr J Med. 2000 Jan-Mar; 19(1): 19-22

47. Nyame PK, Jumah KB et al. Computerized tomography scan of the head in the evaluation of stroke in Ghanaians. East Afr.Med J 1998 Nov; 75: 17-19 